\title{
Articulação entre redes de atenção a crianças e adolescentes toxicodependentes
}

\author{
Articulation among care networks for drug addicted children and adolescents \\ Articulación entre redes de atención a niños y adolescentes drogodependientes
}

Recebido: 03/01/2022 | Revisado: 07/01/2022 |Aceito: 19/01/2022 | Publicado: 21/01/2022

\author{
Giancarlo Tozo \\ ORCID: https://orcid.org/0000-0002-9539-5775 \\ Universidade Estadual do Oeste do Paraná, Brasil \\ E-mail: giancarlo_tozo@yahoo.com.br \\ Gicelle Galvan Machineski \\ ORCID: https://orcid.org/0000-0002-8084-921X \\ Universidade Estadual do Oeste do Paraná, Brasil \\ E-mail: gmachineski@gmail.comr \\ Beatriz Rosana Gonçalves de Oliveira Toso \\ ORCID: https://orcid.org/0000-0001-7366-077X \\ Universidade Estadual do Oeste do Paraná, Brasil \\ E-mail: lb.toso@gmail.com
}

\begin{abstract}
Resumo
Objetivou-se compreender a articulação entre a rede de atenção psicossocial e a rede de proteção social de um município no Oeste do Paraná, no atendimento de crianças e adolescentes toxicodependentes. Trata-se de pesquisa qualitativa, descritiva e exploratória. A coleta de dados foi documental e por meio de entrevistas semiestruturadas com seis trabalhadores das redes, no período de janeiro a dezembro de 2018, e submetidos a análise temática. Identificou-se a articulação entre as redes por meio da intersetorialidade, da horizontalidade, da cooperação e da integração no atendimento a crianças e adolescentes usuárias de substâncias psicoativas. E a partir dos dispositivos legais dos diversos setores envolvidos e de instrumentos, como o fluxograma de atendimento a drogadição e a ficha de referência e contrarreferência, além da comunicação entre os trabalhadores, contribuindo para a superação de práticas setoriais fragmentadas.
\end{abstract}

Palavras-chave: Colaboração intersetorial; Serviços de saúde mental; Criança; Adolescente; Toxicômanos.

\begin{abstract}
The objective was to understand the articulation between the psychosocial care network and the social protection network of a municipality in Western Paraná, in the care of drug addicted children and adolescents. It is a qualitative, descriptive, and exploratory research. Data collection was documentary and through semi-structured interviews with six network workers, from January to December 2018, and submitted to thematic analysis. The articulation between the networks was identified through intersectoriality, horizontality, cooperation, and integration in the care of children and adolescents who use psychoactive substances. And based on the legal provisions of the various sectors involved and instruments, such as the flowchart for drug addiction and the reference and counter-reference form, in addition to communication between workers, contributing to overcome fragmented sectoral practices.
\end{abstract}

Keywords: Intersectoral collaboration; Mental health services; Child; Adolescent; Drug users.

\section{Resumen}

El objetivo fue comprender el vínculo entre la red de atención psicosocial y la red de protección social de un municipio del oeste de Paraná, en la atención de niños y adolescentes drogadictos. Es una investigación cualitativa, descriptiva y exploratoria. La recolección de datos fue documental y a través de entrevistas semiestructuradas con seis trabajadores de la red, de enero a diciembre de 2018, y sometidas a análisis temático. La articulación entre redes se identificó a través de la intersectorialidad, la horizontalidad, la cooperación y la integración en el cuidado de los niños y adolescentes consumidores de sustancias psicoactivas. $\mathrm{Y}$ en base a las disposiciones legales de los distintos sectores involucrados e instrumentos, como el diagrama de flujo para las drogodependencias y el formulario de referencia y contrarreferencia, además de la comunicación entre los trabajadores, contribuyendo a superar prácticas sectoriales fragmentadas.

Palabras clave: Colaboración intersectorial; Servicios de salud mental; Niño; Adolescente; Consumidores de drogas.

\section{Introdução}

A problemática das Substâncias Psicoativas (SPA), dada sua complexidade, não pode ser tratada de forma 
fragmentada e simplista, requerendo ações igualmente complexas, numa perspectiva integral e intersetorial. Importantes instituições e organizações formuladoras de políticas ligadas ao setor saúde também defendem a necessidade da articulação intersetorial como forma de reverter à fragmentação existente, no que diz respeito às políticas de saúde de forma geral e, mais especificamente, de saúde mental e de drogas (Castell-Florit \& Gispert, 2012; Albuquerque, Azevedo, \& Nobre, 2016).

A partir da década de noventa, no Brasil, programas federais de áreas como saúde, educação e serviço social traziam consigo a articulação das ações setoriais de políticas públicas como pressuposto (Monnerat \& Souza, 2014). Dentre as redes de saúde existentes, vinculadas a temática tratada nesse estudo, encontra-se a Rede de Atenção Psicossocial (RAPS) que tem como diretriz a intersetorialidade. Essa rede se apresenta como alternativa, no que se refere às formas de organização ou reorganização do processo de trabalho e de cuidado para o público a que se destina (Brasil, 2011).

Para a abordagem de um problema polissêmico como é o abuso de SPA na sociedade, e como tentativa de superar as ações focalizadas, destaca-se o direcionamento no sentido da intersetorialidade a partir da construção de redes de atenção intersetoriais. Estas buscam articular serviços e programas, governamentais e não governamentais, com o objetivo de superar práticas fragmentadas no enfrentamento de demandas complexas, a exemplo do uso de SPA por crianças e adolescentes (Ferrari \& Tavares, 2016).

Em estudo realizado em serviços da Rede de Atenção Psicossocial ao adolescente em município do Rio do Grande do Sul, os autores concluíram que há necessidade de as intervenções realizadas com adolescentes usuários estarem pautadas na perspectiva interdisciplinar, intersetorial e com profissionais qualificados, a fim de potencializar as ações de atenção à saúde para atender essa demanda (Paim, Dalla Porta, Sarzi, Cardinal, \& Siqueira, et al., 2017), como se acredita nesse estudo.

O município em que a pesquisa foi desenvolvida conta com sua RAPS e, desde 2010, constrói a Rede de Atenção e Proteção Social (de agora em diante mencionada somente como REDE, devido a coincidência das siglas), composta por profissionais de entidades governamentais e não governamentais vinculadas às diversas políticas públicas, incluindo a RAPS. Tem como pressuposto a construção de uma rede intersetorial, mediante a compreensão dos processos organizacionais dos equipamentos sociais, tendo em vista a ampliação da comunicação e articulação entre os serviços, para os encaminhamentos mais adequados às necessidades sociais (Cascavel, 2020).

Entretanto, observa-se avanços e retrocessos na superação das práticas fragmentadas, pois estas são vinculadas ao pensamento científico hegemônico, que valoriza a divisão dos campos do saber e práticas (Costa, Mota, Paiva, \& Ronzani, 2015). Permanece ainda a ausência de diálogo/interação entre atores e setores que constituem as redes de saúde, polarizações entre serviços ambulatoriais ou hospitalares e falta de comunicação entre os diferentes pontos de atenção. Portanto, as práticas intersetoriais têm como desafio o enfrentamento desse cenário.

Tendo em vista o exposto, questiona-se: "Como acontece a articulação entre a RAPS e a REDE para o atendimento de crianças e adolescentes usuários de SPA em município de médio porte da região Oeste do Paraná?"

Para responder à questão do estudo, seu objetivo foi compreender a articulação entre a rede de atenção psicossocial e a rede de proteção social de um município no Oeste do Paraná, no atendimento de crianças e adolescentes toxicodependentes.

\section{Metodologia}

O processo de construção da experiência intersetorial na realidade estudada é resultado de um trabalho humano complexo, social, provisório e histórico e por isso deve ser entendido a partir de sua totalidade social e como uma construção histórica (Minayo, 2014). Com essa compreensão, dado a natureza do fenômeno optou-se por realizar uma pesquisa do tipo qualitativa, descritiva e exploratória, desenvolvida como dissertação de mestrado.

Para tanto, foram utilizadas as técnicas de pesquisa bibliográfica, documental, e entrevistas semiestruturadas com seis 
Research, Society and Development, v. 11, n. 2, e14911225321, 2022

(CC BY 4.0) | ISSN 2525-3409 | DOI: http://dx.doi.org/10.33448/rsd-v11i2.25321

trabalhadores dos serviços que compõem as redes e atendem crianças e adolescentes usuários de SPA, que foram escolhidos intencionalmente, sendo pelo menos um integrante de cada serviço componente da rede, com vistas ao alcance do objetivo.

Os profissionais incluídos foram representantes de serviços das políticas públicas diretamente relacionadas ao atendimento de crianças e adolescentes usuários de SPA, que participavam das redes há pelo menos seis meses, tendo em vista a necessidade de conhecimento sobre o funcionamento de ambas, rede de atenção psicossocial e rede de proteção social.

Foram entrevistados profissionais do Centro de Atenção Psicossocial - Álcool e Drogas (CAPS AD) e da Unidade de Desintoxicação vinculada a um hospital de ensino público, ambos os serviços de saúde especializados no atendimento a usuários de álcool e outras drogas, conforme a Portaria MS/GM 30.88/11(4), que são componentes da RAPS. Além de profissionais que integravam outros serviços que também atendem essa população, sendo eles o Programa de Prevenção e Combate à Evasão Escolar, o Serviço Auxiliar da Infância e Juventude (SAI), o Conselho Tutelar (CT) e o Centro de Referência Especializado de Assistência Social II (CREAS II).

Lembrando que o CAPS AD e a unidade de desintoxicação hospitalar juntamente com os serviços do Programa de Prevenção e Combate à Evasão Escolar, do Serviço Auxiliar da Infância e Juventude (SAI), do Conselho Tutelar (CT) e do Centro de Referência Especializado de Assistência Social II (CREAS II) são serviços que compõem a REDE do município em estudo.

Importante ressaltar que as crianças e adolescentes usuários de SPA são atendidas no CAPS AD, visto que esse é o serviço especializado para essa clientela, e não no Centro de Atenção Psicossocial Infantil (CAPSi) que se direciona ao atendimento especializado de outros transtornos mentais e comportamentais na infância e adolescência.

E a unidade de desintoxicação é direcionada para o atendimento de crianças e adolescentes usuários de SPA, que são encaminhados, em sua maioria, de forma compulsória via central de leitos do estado do Paraná e trabalha articulada com a RAPS dos municípios de origem dos usuários e com a RAPS e a REDE do município do estudo visando a intersetorialidade das ações. O município da pesquisa ainda não dispõe de unidade de acolhimento infanto-juvenil e o atendimento dos usuários se dá, em sua maioria, pela atenção básica e CAPS AD.

As entrevistas semiestruturadas e gravadas foram realizadas no período de janeiro a abril de 2018. As questões norteadoras contemplaram a compreensão dos profissionais a respeito da articulação intersetorial no cotidiano do cuidado a crianças e adolescentes usuários de SPA; o trabalho em rede no município e; os instrumentos intersetoriais, ficha de referência e contrarreferência e o fluxograma utilizado pelos serviços. Os profissionais foram identificados pela letra E seguida do número de ordem da entrevista, sendo E1, E2 e assim sucessivamente.

A coleta dos dados documentais ocorreu no período de junho a dezembro de 2018. Os documentos foram identificados da seguinte forma: Atas: Ata A e assim sucessivamente, até o último documento; Ofícios: Ofício Expedido de número um - OFE1 e assim sucessivamente até o último documento. Ofício Recebido de número um - OFR 1 e assim sucessivamente até o último documento; Publicações da REDE como o Manual de Orientações Básicas - MOB 2010 e Caderno de Orientação Básica - COB 2015; Livros de Registros do Programa de Capacitação: Volume I, $1^{\circ}$ Etapa - LR 1; Volume II, $1^{\circ}$ Etapa - LR 2 e assim sucessivamente até o último livro, acrescido da página de onde se encontravam os dados, quando necessário, sendo que para páginas sem número, foi utilizada a sigla p.s.n; Fluxograma de drogadição - Fx 1 e; Ficha de Referência e Contrarreferência - FIRC.

Para a análise e interpretação dos dados utilizou-se a técnica de Análise Temática seguindo as etapas: pré-exploração do material ou de leituras flutuantes; seleção das unidades de análise (ou de significados); e categorização e subcategorização, manualmente, sem auxílio de softwares de análise qualitativa de dados. Os resultados foram discutidos a luz da literatura sobre o tema, seguindo o referencial do materialismo histórico e buscando compreender o fenômeno, partindo de sua construção histórica, na totalidade (Minayo, 2014). 
Foram respeitados os aspectos éticos da pesquisa envolvendo seres humanos, sendo que o estudo foi aprovado pelo Comitê de Ética em Pesquisa sob parecer nº 2.195.173/17 e CAAE nº 70756017.7.0000.0107.

\section{Resultados}

A partir da análise dos documentos e entrevistas foi elaborada a categoria A articulação entre a RAPS e os demais serviços que atendem crianças e adolescentes usuárias de SPA, a qual contempla as seguintes unidades de análise: os serviços da RAPS que atendem diretamente crianças e adolescentes usuárias de SPA; a intersetorialidade entre a RAPS e a REDE para os atendimentos; conceitos de horizontalidade, cooperação, integração, intersetorialidade; diálogo, a troca de informações, a relação entre parceiros para operacionalizar a relação entre os serviços; articulação entre os serviços e a REDE com características como o diálogo, a troca de informações, a relação entre parceiros e; o relacionamento entre as equipes e serviços ocorre também com o objetivo de obtenção de informações sobre condições preexistentes e ações já desenvolvidas.

Na unidade de análise sobre os serviços da RAPS que atendem diretamente crianças e adolescentes usuárias de SPA, identificou-se, tendo como base os documentos analisados, que os serviços de saúde, componentes da RAPS, que participam da REDE são CAPS AD para atendimento no território e a unidade de desintoxicação do hospital de ensino público para casos graves (MOB 2010, COB 2015, OFR 08, OFR 22).

A pesquisa documental demonstrou que os profissionais do CAPS AD participaram tanto como ministrantes quanto como participantes/ouvintes de todas as etapas das capacitações promovidas pela REDE em 2016, assim como os que fazem parte do Serviço Integrado de Saúde Mental do Paraná (SIM/PR) e gerência de saúde mental do município (LR I, p.s.n; LR 4, p.s.n). Já a unidade de desintoxicação hospitalar participou apenas como ouvinte desses momentos (LR 4, p. 85 - 266).

Na apresentação da Secretaria Municipal de Saúde, realizada na $1^{\text {a }}$ etapa da capacitação, não houve destaque para RAPS, a qual constou apenas como um serviço descrito no organograma da secretaria (LR 2, p. 154). Na segunda etapa, houve avanços e o funcionamento desse serviço, juntamente com os demais serviços da secretaria, foi apresentado. O CAPS AD, que no município do estudo atende apenas crianças e adolescentes, foi assim descrito:

Assistência em Saúde Mental, (...) Centro de Atenção Psicossocial - Álcool e Drogas (CAPS ad), (...) oferece atendimento a crianças e adolescentes do Município (...), usuários de álcool e outras drogas. Realiza atividades terapêuticas e preventivas, proporcionando tratamento, habitação e ressocialização junto a família e comunidade. (LR 5, p. 165)

Quanto a intersetorialidade entre a RAPS e a REDE para os atendimentos, observa-se que ações intersetoriais, preconizadas como diretriz para o funcionamento de uma rede setorial, foram adotadas pela RAPS no município do estudo, no que diz respeito ao atendimento de crianças e adolescentes usuários de SPA. Tal articulação entre as redes (RAPS e REDE) se deu por meio do Fluxograma de Atendimento à Criança e Adolescente em Drogadição, utilizado pelos serviços como ferramenta para nortear o processo de trabalho. Os serviços elencados no fluxograma são:

CRAS [Centro de Referência de Assistência Social], CREAS [Centro de Referência Especializado de Assistência Social] I, CREAS II, Casa de Passagem Masculina, Casa de Passagem Feminina, Centro da Juventude, Programa Família Acolhedora, Serviços Especializados em Abordagem Social, CENSE [Centro de Sócio Educação] I e II, Semiliberdade, EURECA [Serviço de Convivência e Fortalecimento de Vínculos para crianças e adolescentes] I e II, Conselho Tutelar, Escola Municipal, Escola Estadual, Programa Evasão Escolar, UBS [Unidade Básica de Saúde], CAPS AD, UPA [Unidade de pronto-Atendimento] Pediátrica, hospital. (FX 1)

Dos 18 serviços mencionados no Fluxograma de Drogadição, 13 possuem indicação direta para encaminhar para o CAPS AD, sendo eles Centro de Referência de Assistência Social (CRAS), CREAS II, Casa de Passagem Masculina, Casa de 
Passagem Feminina, Centro da Juventude, Programa Família Acolhedora, Centro de Socio Educação I e II (CENSE), Semiliberdade, Serviço de Convivência e Fortalecimento de Vínculos (EURECA) I e II, Conselho Tutelar, Escola Municipal, Programa Evasão Escolar, Unidades Básicas de Saúde (UBS), CAPS AD, Unidade de Pronto Atendimento (UPA) Pediátrica, unidade de desintoxicação do hospital de ensino. Apenas dois serviços possuem indicação para encaminhamentos ao hospital, sendo eles a UPA Pediátrica e o CAPS AD (FX 1). Por sua vez o CAPS AD pode referenciar para Unidade Básica de Saúde (UBS) ou Unidade de Saúde da Família (ESF), internamento hospitalar especializado e ainda, para outros setores como esporte, cultura, assistência social, escola, conselho tutelar.

O referido fluxograma traz de forma esquemática o percurso que será percorrido, quando identificadas situações de uso de SPA por crianças e adolescentes, orientando a conduta dos profissionais das diferentes políticas públicas. Traz ainda as ações e encaminhamentos necessários a serem desenvolvidos pelos serviços que compõem determinada política pública. As políticas públicas descritas como "porta de entrada” são: Política de Assistência Social, Política de Educação, Política de Saúde, Política de Esporte, Política de Cultura e ainda, Conselho Tutelar, Ministério Público, Poder Judiciário e Defensoria Pública.

$\mathrm{Na}$ pesquisa documental evidenciou-se uma concepção de articulação intersetorial pautada nos conceitos de horizontalidade, cooperação, integração, intersetorialidade, diálogo, a troca de informações, a relação entre parceiros para operacionalizar a relação entre os serviços, conforme o documento a seguir:

Independente de estar relacionado a esse serviço ou aos demais, objetiva-se facilitar os atendimentos e procedimentos que acionam a Rede de Proteção de forma que todos estejam envolvidos na garantia de direitos. Os componentes da Rede de Proteção primam pela horizontalidade das relações entre seus membros, buscando maior cooperação, valorizando a integração e a intersetorialidade, ampliando parcerias e envolvendo instituições governamentais, não governamentais e a comunidade (MOB 2010).

A respeito da articulação entre os serviços e a REDE com características como o diálogo, a troca de informações, a relação entre parceiros, destacam-se os depoimentos:

A gente convida o outro serviço, a gente encaminha a ficha e não deixa de usar o telefone [...]. (E 1)

A nossa comunicação básica, assim, o diálogo, se dá por meio da ficha de referência e contrarreferência. [...]. Então eu acho que é importante esse diálogo permanecer e quando você encaminha uma ficha de referência acho que é essencial que seja precedido ou de uma ligação telefônica: estou encaminhando um caso, porque a rede pressupõe já conhecimento das pessoas, então, quando eu ligo, eu já falo o nome da pessoa, já sei o nome da pessoa com quem eu estou falando. Ligações telefônicas ou e-mails, que a gente manda um e-mail também complementando, o que você tiver a mais é sempre assim essencial. (E 4)

[...] a escola ou o colégio, eles encaminham por e-mail a ficha, a gente recebe todos os dias, um monte de encaminhamento [...].(E 6)

[...] nós estamos o tempo todo identificando situações que ferem alguns direitos, [...], o nosso trabalho, o tempo todo, é fazer o contraponto, a gente entra em contato, muitas vezes, telefônico [...] então a gente tá o tempo todo fazendo essa articulação com os serviços, então, nós estamos totalmente relacionados, é... a essa intersetorialidade. (E 2)

O nosso serviço tem um trabalho permanente de visitação nos outros órgãos, também dos órgãos para com ele, nesse diálogo, estarmos discutindo tanto o fluxo como qual é a demanda que é encaminhada. (E 4)

E o relacionamento entre as equipes e serviços ocorre também com o objetivo de obtenção de informações sobre condições preexistentes e ações já desenvolvidas. Essas situações são verificadas nas seguintes falas: 
UBS, para fazer uma visita domiciliar, ver a situação em loco, porque a demanda aqui é muito grande e o nosso objetivo é atender a demanda aqui, só que eu preciso saber também desse feedback, dessa questão mais ampla, então assim, eu faço diariamente a gente faz contato com os serviços da rede para saber de situações, porque nem sempre o que aparece para nós é o que realmente é, então assim, às vezes, são trazidas certas demandas, e a gente vai ver com os serviços que estão ali mais próximos, e é outra situação. (E 3)

As escolas, quando elas identificam cinco faltas consecutivas ou sete faltas alternadas, elas fazem a ação delas [...] em ela não tendo resultado, sucesso, ela manda para evasão (notificação de evasão escolar). (E 4)

Nosso serviço ele tem uma atuação em rede, fazendo encaminhamentos, recebendo encaminhamentos e procura essa articulação entre os diferentes serviços das diferentes políticas. [...] Mas quando o adolescente entra, na entrevista inicial, é identificado as demandas dos adolescentes e essas demandas daí nós acionamos a rede [...]. (E 5)

A maioria é escola que nos informa, a escola, até às vezes a unidade básica de saúde, porque ela vai visitando as famílias, as ACS, as agentes de saúde, visitam as famílias, percebem que aquela mãe, aquele pai tão sendo judiado, tão ali sofrendo, tão tendo problema ali com o filho, se usando droga, e eles não sabem o que fazer, então as ACS geralmente passam para a assistente social ou enfermeira, coordenadora da UBS, que vem nos comunicar esse fato. (E 6)

\section{Discussão}

Dentre os serviços da RAPS que atendem crianças e adolescentes usuários de SPA, o CAPS AD constitui-se como serviço substitutivo, sendo definido na Portaria MS/GM 3038/2011 como ponto especializado da Atenção Psicossocial no atendimento a adultos ou crianças e adolescentes usuários de SPA, com atendimento aberto, regionalizado e comunitário. E a ala de desintoxicação do hospital de ensino público pode ser classificada como o componente hospitalar da RAPS, conforme disposto na Portaria MS/GM 3588/2017 (Brasil, 2017).

A RAPS tem como referência a Reforma Sanitária, que embasou a Reforma Psiquiátrica Brasileira segundo a Lei 10216/2001. Articula os pontos de atenção a saúde para portadores de transtorno mental e usuários de SPA. A referida Lei possibilitou uma configuração muito favorável e promissora para a saúde mental no Sistema Único de Saúde (SUS), pois redirecionou o modelo de assistência em saúde mental (Costa, Medeiros, Loures, Silva, \& Ronzani, et al., 2017; Amarante \& Nunes, 2018; Rameh-de-Albuquerque, Lira, Costa, \& Nappo, 2017).

No que se refere a atenção ao usuário de SPA, no âmbito do SUS, a Política Nacional de Atenção Integral aos Usuários de Álcool e Outras Drogas, instituida após 2004, é considerada como conquista da Reforma Psiquiátrica Brasileira, pois redefine e amplia a atenção integral a essa população (Rameh-de-Albuquerque, Lira, Costa, \& Nappo, 2017).

No entanto, percebe-se que a partir de 2016, a legislação que se refere às políticas de saúde mental apresenta retrocessos no que se refere ao redirecionamento do modelo assistencial, com incentivos para hospitais psiquiátricos e as comunidades terapêuticas (Teixeira, Ramôa, Engstrom, \& Ribeiro, 2017; Brasil, 2019a; Brasil, 2019b). Isso contribui para o cerceamento do indivíduo em sofrimento psíquico e o cuidado é baseado na patologia, possibilitando práticas manicomiais, desconsiderando a integralidade, a intersetorialidade e o território como lugar de atenção à saúde mental.

Ademais, para entender uma rede assistencial sobre drogas, deve-se considerar sua conformação em relação a RAPS, na qual os pontos de atenção especializados devem estar articulados aos demais componentes e associados a rede de serviços de saúde e sociais que tenham como objetivo a reabilitação e reinserção social. Assim, crianças e adolescentes atendidos no CAPS AD do município que, segundo a avaliação da equipe multiprofissional, necessitam do atendimento em regime fechado, quando as possibilidades do território não foram suficientes, são incluídos na Central de Leitos do Estado. Havendo vaga, esses são internados na referida unidade hospitalar que, por sua vez, após a alta hospitalar, os encaminha ao serviço ambulatorial de referência e acompanhamento no território (Brasil, 2017; Mombelli, Marcon, \& Costa, 2010).

Os serviços integrantes da RAPS se organizam e participam da organização da REDE, sendo que há protagonismo do 
CAPS AD nesse processo, visto que este visa à superação das práticas fragmentadas, em consonância a políticas públicas. Esse serviço tem a responsabilidade de gerenciar fluxos de pacientes e para isso se articula com os outros componentes da rede. Acredita-se que dessa forma, e corroborando com Costa, Ronzani, e Colugnati (2018), estimula-se a constituiçao de redes intersetoriais.

No município estudado, os serviços especializados para o tratamento de usuários de SPA são apenas o CAPS AD e a unidade de desintoxicação hospitalar, demonstrando a coerência do atendimento com o modelo assistencial proposto pela Reforma Psiquiátrica e com o disposto nas principais políticas nacionais sobre o tema. Essa compreensão está atrelada ao entendimento de que tende a atenção extramuros, recorrendo à internação apenas quando os serviços do território se mostram insuficientes. Esse contexto se assemelha aquele encontrado no levantamento da rede de atenção aos usuários de drogas em um município de médio porte no Brasil, no qual se observou que a maior parte dos serviços era de cunho generalista (Brasil, 2017).

Essa forma de operacionalizar o trabalho intersetorial, com características de rede, encontra referência na literatura da área cujo entendimento aponta para a construção de outra forma de relação entre setores, com vistas à superação da fragmentação setorial, típica da justaposição de diversas profissões de um mesmo setor, no caso o da saúde, cada qual com distintos processos de trabalho. Importante destacar que, geralmente, essas relações são apresentadas como hierarquizadas, burocráticas, fragmentadas, indicando a necessidade de mudanças de concepções, valores e práticas das organizações públicas que favoreçam a construção de relacionamentos autônomos, horizontais, democráticos, com atitudes cooperativas (Ferrari \& Tavares, 2016; Lavoratti, 2016).

Nesse sentido, estudo de revisão integrativa sobre as ações de intersetorialidade na saúde mental destaca que, tanto a literatura nacional quanto a internacional, apresentam uma diversidade de ações consideradas intersetoriais tais como: intervenções na escola/instituição de ensino; ações educativas; parcerias com ONGs; fóruns de discussões; subsídios sociais (previdência, habitação, saúde); ações de inclusão no trabalho; intervenções na comunidade; intervenção domiciliar; acolhimento das instituições religiosas; e, lazer. E, para que a intersetorialidade aconteça, são necessárias a articulação, a comunicação ampla e a responsabilização compartilhada pelos casos de saúde mental, o que pode ser alçando via formação profissional e educação social, quanto à qualidade de vida e necessidade ampla do sujeito (Silva, Olschowsky, Silva, Pavani, \& Wetzel, 2019).

O relacionamento da REDE com os serviços, nesse estudo, difere do que foi encontrado em pesquisa que avaliou a rede de proteção e cuidado a crianças e adolescentes usuárias de SPA do município de Betim/MG. Os autores encontraram que a falta de articulação e diálogo entre os serviços é agravada pela existência de poucos espaços para definir ações conjuntas, pois cada serviço fica limitado a sua função específica. Nesse sentido, entende-se que os contatos via telefone e e-mail, além de instrumentos como a Ficha Intersetorial de Referência e Contrarreferência são necessários, pois, para a integração do trabalho intersetorial deve ocorrer primeiramente um diálogo inicial entre os serviços, para que possa haver comunicação efetiva (Passos, Reinaldo, Barboza, Braga, \& Ladeira, 2016; Vieira \& Hasse, 2017).

Ao mesmo tempo em que instrumentos dessa natureza podem limitar a liberdade criativa do trabalhador durante o exercício de suas funções no processo de trabalho em saúde, podem também ser utilizados como ferramentas que permeiam a comunicação e resultam em melhor cuidado para o usuário, na interrelação entre os microprocessos de trabalho, em que sobressai o protagonismo dos trabalhadores e usuários da saúde, nos seus espaços de trabalho e relações, guiado por diversos interesses, que organizam suas práticas e ações na saúde (Franco, 2015).

Os profissionais que fazem parte da REDE compreendem a intersetorialidade, operacionalizada em uma rede intersetorial, como instrumento para obtenção da integralidade, além de perceber a determinação social no processo saúdeadoecimento. Além disso, essa articulação é pautada por práticas interdisciplinares, pois a elaboração dos projetos terapêuticos 
dos usuários está embasada em diversas áreas do conhecimento. Cada setor assistencial e seus profissionais contribuem de forma parcelar, específica e independente dentro de um projeto assistencial em comum (Castell-Florit \& Gispert, 2012; Carmo \& Guizardi, 2017).

Portanto, observa-se que a relação entre os serviços da RAPS e desses com os demais setores, é mediado pelo trabalho desenvolvido pela REDE, e ocorre em uma perspectiva de rede intersetorial, com a adoção dos instrumentos intersetoriais desenvolvidos com o intuito de se alcançar a integralidade na assistência aos jovens usuários de SPA, como os Fluxogramas e a Ficha Intersetorial de Referência e Contrarreferência.

Existe consenso que o uso de drogas por crianças e adolescentes traz impactos no seu desenvolvimento biopsicossocial, podendo ser considerado um complexo problema de saúde pública. Pesquisadores de áreas como saúde, educação e serviço social e profissionais vinculados diretamente à assistência de crianças e adolescentes usuárias de SPA, concordam que essa situação, por ser multifacetada, requer ações intersetoriais para seu enfrentamento (Gonçalves \& Albuquerque, 2016; Costa et al., 2015; Brasil, 2017).

Esse estudo demonstra a tentativa peculiar de profissionais em articular de forma intersetorial os serviços de atenção em saúde mental a crianças e adolescentes usuários de SPA da RAPS e da REDE do município estudado. Experiências como essas têm sido desenvolvidas no país desde a década de 1990, com diferentes características que buscam romper com a fragmentação setorial. No entanto, ainda se encontram ações fragmentadas, desarticuladas e paralelas, resultado entre outras coisas da forma como tradicionalmente e culturalmente ainda se organizam as políticas públicas no Brasil, dentre elas as de saúde e assistência social e da forma como se operacionaliza o sistema de saúde. Assim, os programas tendem a ser verticalizados e hierarquizados, principalmente no que diz respeito à prevenção e ao combate das SPA, embora suas ações devam ser locais (Monnerat \& Souza, 2014).

Como limitações do estudo aponta-se o fato de não terem sido ouvidos todos os personagens de todos os serviços componentes do cuidado, além de representantes de usuários, de familiares, dos serviços não governamentais e da atenção primária, no município do estudo, em função das limitações do tempo e do pesquisador, sendo essas oportunidades de investigações futuras. Soma-se a isso a indisponibilidade de parte dos arquivos documentais da REDE e do Núcleo da Criança e Adolescente e a escassez de publicações referentes ao tema. Assim, dar voz a esses sujeitos e aos adolescentes usuários de SPA pode ajudar a construir uma visão mais ampliada sobre o fenômeno. Desse modo, esses resultados dizem respeito somente ao ambiente e aos participantes que integraram o estudo, não sendo generalizáveis.

\section{Considerações Finais}

Foi possível observar nesse estudo o desenvolvimento de ações no sentido de reunir diferentes setores, governamentais e não governamentais para o enfrentamento de problemas sociais complexos, como é o caso do uso e abuso de SPA por crianças e adolescentes. Percebeu-se que a forma como se relacionam os serviços que compõe a RAPS e os demais que constituem a REDE seguem além dos dispositivos legais, os Fluxogramas de Atendimento a Drogadição e a Ficha de Referência e Contrarreferência, ambos os instrumentos intersetoriais. Ademais são realizados contatos entre os trabalhadores via e-mail e/ou telefone. Ressalta-se que essa articulação tem referências como a horizontalidade, cooperação, integração, intersetorialidade, diálogo, relação entre parceiros, troca de informações para obtenção de condições preexistentes e ações desenvolvidas.

Nota-se, nesse contexto, que o CAPS AD procura cumprir seu papel de articulador da rede, como ponto especializado da atenção psicossocial no atendimento a esse grupo específico, no que se refere à intersetorialidade, exercendo o protagonismo convergente ao modelo assistencial proposto pela Reforma Psiquiátrica Brasileira. Dessa forma, indica-se a 
Research, Society and Development, v. 11, n. 2, e14911225321, 2022

(CC BY 4.0) | ISSN 2525-3409 | DOI: http://dx.doi.org/10.33448/rsd-v11i2.25321

realização de estudos futuros envolvendo todos os atores envolvidos na construção da rede de apoio, incluindo-se os adolescentes, para ampliar a compreensão sobre a temática.

Nesse sentido, compreendeu-se a articulação da RAPS com a REDE no município do estudo, no atendimento de crianças e adolescentes usuários de SPA, na perspectiva da intersetorialidade como experiência concreta, em que a construção da REDE se constitui num processo histórico em desenvolvimento. Essa experiência pode contribuir para o fortalecimento de políticas públicas que visem à integralidade do cuidado a essa clientela.

\section{Referências}

Alburquerque, C. S., de Azevedo, E. E. B., \& Nobre, M. C. de Q. (2016). Drogas, "Questão Social” e Políticas Sociais: entre os direitos de cidadania e a criminalização da pobreza. In: Gonçalves, A. M. \& Albuquerque, C. S. Drogas e proteção social: os desafios da intersetorialidade. Expressão Gráfica e Editora, Fortaleza. (pp. 35-63).

Amarante, P., \& Nunes, M. O. (2018) A reforma psiquiátrica no SUS e a luta por uma sociedade sem manicômios. Ciência e saúde coletiva, 23(6):2067-2074. http://www.scielo.br/scielo.php?script=sci_arttext\&pid=S1413-81232018000602067\&lng=pt.

Brasil, Ministério da Saúde. (2011) Portaria n ${ }^{\circ}$ 3.088. Institui a Rede de Atenção Psicossocial para pessoas com sofrimento ou transtorno mental e com necessidades decorrentes do uso de crack, álcool e outras drogas, no âmbito do Sistema Único de Saúde. Diário Oficial da União. 26 Dez 2011.

Brasil. Ministério da Saúde. (2017). Portaria n 3.588. Altera as Portarias de Consolidação n 3 e n ${ }^{\circ}$ 6, de 28 de setembro de 2017 , para dispor sobre a Rede de Atenção Psicossocial, e dá outras providências. Diário Oficial da União. 22 Dez 2017.

Brasil. Ministério da Saúde (2019a). Decreto n ${ }^{\circ}$ 9.761. Aprova a Política Nacional sobre drogas. Brasília: Diário Oficial da União. 11 abr 2019. http://www.planalto.gov.br/ccivil_03/_ato2019-2022/2019/decreto/D9761.htm.

Brasil. Ministério da Saúde. (2019b). Secretaria de Atenção à Saúde. Departamento de Ações Programáticas Estratégicas. Coordenação-Geral de Saúde Mental, Álcool e outras Drogas. Nota técnica $\mathrm{n}^{\circ} 11$ de 04 de fevereiro de 2019. Brasília: Ministério da Saúde. http://pbpd.org.br/wpcontent/uploads/2019/02/0656ad6e.pdf \&gt.

Carmo, M. E., \& Guizardi, F. L. (2017). Desafios da intersetorialidade nas políticas públicas de saúde e assistência social: uma revisão do estado da arte. Physis, 27(4):1265-1286. http://www.scielo.br/scielo.php?script=sci_arttext\&pid=S0103-73312017000401265\&lng=pt.

Cascavel. Prefeitura Municipal (2020). Rede de Proteção e Atenção Social. http://www.cascavel.pr.gov.br/conselhos/intersetorial/pagina.php?id=561.

Castell-Florit, S. P., \& Gispert, A. E. (2012). Intersectorialidad en el contexto socioeconómico cubano y sus implicaciones en la salud de la población. Revista Cubana de Salud Pública, 38(5):823-833. https://www.redalyc.org/articulo.oa?id=21425053015.

Costa, P. H. A. da, Mota, D. C. B., Paiva, F. S. de, \& Ronzani, T. M. (2015). Desatando a trama das redes assistenciais sobre drogas: uma revisão narrativa da literatura. Ciência e saúde coletiva, 20(2): 395-406. http://www.scielo.br/scielo.php?script=sci_arttext\&pid=S1413-81232015000200395\&lng=pt.

Costa, P. H. A. da, Ronzani, T. M., \& Colugnati, F. A. B. (2018). No meio do caminho tinha um CAPSAD: centralidade e lógica assistencial da rede de atenção aos usuários de drogas. Ciência e saúde coletiva, 23(10): 3233-3245. http://www.scielo.br/scielo.php?script=sci_arttext\&pid=S1413$81232018001003233 \& \operatorname{lng}=$ pt.

Costa, P. H. A. da, Medeiros, A. X., Loures, B. P., Silva, W. M. D., Ronzani, T. M., \& Colugnati, F. A. B. (2017). Levantamento da rede de atenção aos usuários de drogas: Um estudo exploratório. Estudos de Psicologia (Natal), 22(2), 160-171. https://dx.doi.org/10.22491/1678-4669.20170017.

Ferrari, A. K., \& Tavares, G. M. (2016). A aposta na tessitura de redes como inovação do trabalho no campo sociojurídico. Serviço Social \& Sociedade, (125): 101-123. http://www.scielo.br/scielo.php?script=sci_arttext\&pid=S0101-66282016000100101\&lng=pt\&tlng=pt.

Franco, T. B. (2015). Trabalho criativo e cuidado em saúde: um debate a partir dos conceitos de servidão e liberdade. Saúde e Sociedade, 24(1):102-14. https://www.scielosp.org/pdf/sausoc/2015.v24supp11/102-114.

Lavoratti, C. (2016). Tecendo a rede de proteção às crianças e adolescentes em situação de risco para a violência do município de Curitiba/PR. Revista NEP, 2(3): 1-24. https://revistas.ufpr.br/nep/article/view/47246/28289.

Minayo, M. C. S. (2014). O desafio do conhecimento: pesquisa qualitativa em saúde. 12. ed. São Paulo: Hucitec.

Mombelli, M. A., Marcon, S. S., \& Costa, J. B. (2010). Caracterização das internações psiquiátricas para desintoxicação de adolescentes dependentes químicos. Revista brasileira de enfermagem, 63(5): 735-740. http://www.scielo.br/scielo.php?script=sci_arttext\&pid=S0034-71672010000500007\&lng=pt.

Monnerat, G. L., \& Souza, R. G. (2014) Intersetorialidade e políticas sociais: um diálogo com a literatura. In: Monnerat, G. L., Almeida, N. L. T., \& Souza, R. G. (Org.). Intersetorialidade na agenda das políticas sociais. Campinas, SP: Papel Social (pp. 41-54).

Paim, B, R., Dalla Porta, D., Sarzi, D. M., Cardinal, M. F., \& de Siqueira, D. F. et al. (2017). Atendimento ao adolescente usuário de substâncias psicoativas: papel do centro de atenção psicossocial. Cogitare Enfermagem, (22)1: e48011. 
Research, Society and Development, v. 11, n. 2, e14911225321, 2022

(CC BY 4.0) | ISSN 2525-3409 | DOI: http://dx.doi.org/10.33448/rsd-v11i2.25321

Passos, I. C. F., Reinaldo, A. M. dos S., Barboza, M. A. G., Braga, G. A. R., \& Ladeira, K. E. (2016). A rede de proteção e cuidado a crianças e adolescentes do município de Betim/MG e os desafios do enfrentamento ao uso abusivo de crack, álcool e outras drogas. Pesquisas e Práticas Psicossociais, 11(3), 583601. http://pepsic.bvsalud.org/scielo.php?script=sci_arttext\&pid=S1809-89082016000300005\&lng=pt\&tlng=pt.

Rameh-de-Albuquerque, R. C., Lira, W. L., Costa, A. M., \& Nappo, S. A. (2017) Do descaso a um novo olhar: a construção da Política Nacional de Atenção Integral aos Usuários de Álcool e Outras Drogas como conquista da Reforma Psiquiátrica Brasileira. O caso de Recife (PE). Psicologia em Pesquisa, UFJF, 11(1), 84-96. https://periodicos.ufjf.br/index.php/psicologiaempesquisa/issue/view/1095.

Silva, L. M., Olschowsky, A., da Silva, A. B., Pavani, F. M., \& Wetzel, C. (2019). Intersectoral Actions for Mental Health: An Integrative Review. Revista de Pesquisa: Cuidado é Fundamental Online, 11(3): 763-770. http://seer.unirio.br/index.php/cuidadofundamental/article/view/6824.

Teixeira, M. B., Ramôa, M. de L., Engstrom, E., \& Ribeiro, J. M. (2017). Tensões paradigmáticas nas políticas públicas sobre drogas: análise da legislação brasileira no período de 2000 a 2016. Ciência e Saúde Coletiva, 22(5), 1455-1466. https://doi.org/10.1590/1413-81232017225.32772016.

Vieira, E. M., \& Hasse, M. (2017). Percepções dos profissionais de uma rede intersetorial sobre o atendimento a mulheres em situação de violência. Interface (Botucatu), 21(60): 52-62. https://www.scielo.br/j/icse/a/GXcfNwpDWsKM4rmmnVPf7Ln/abstract/?lang=pt 